\title{
Potential drug-drug interactions associated with adverse clinical outcomes and abnormal laboratory findings in patients with malaria
}

\author{
Sidra Noor, Mohammad Ismail" (iD and Faiza Khadim
}

\begin{abstract}
Background: Hospitalized patients with malaria often present with comorbidities or associated complications for which a variety of drugs are prescribed. Multiple drug therapy often leads to drug-drug interactions (DDIs). Therefore, the current study investigated the prevalence, levels, risk factors, clinical relevance, and monitoring parameters/management guidelines of potential DDls (pDDls) among inpatients with malaria.

Methods: A retrospective cohort study was carried out at two tertiary care hospitals. A total of 398 patients' profiles were evaluated for pDDls using the Micromedex Drug-Rea ${ }^{\circledR}$. Odds ratios were calculated to identify the strength of association between presence of DDIs and potential risk factors via logistic regression analysis. Further, the clinical relevance of frequent pDDIs was investigated.

Results: Of 398 patients, pDDls were observed in 37.2\% patients, while major-pDDls in 19.3\% patients. A total of 325 interactions were found, of which $45.5 \%$ were of major- and $34.5 \%$ moderate-severity. Patients with the most common pDDls were found with signs/symptoms and abnormalities in laboratory findings representing nephrotoxicity, hepatotoxicity, QT interval prolongation, and reduced therapeutic efficacy. The following drug pairs reported the highest frequency of adverse events associated with the interactions; calcium containing products-ceftriaxone, isoniazid-rifampin, pyrazinamide-rifampin, isoniazid-acetaminophen, and ciprofloxacin-metronidazole. The adverse events were more common in patients prescribed with the higher doses of interacting drugs. Multivariate regression analysis showed statistically significant association of pDDIs with 5-6 prescribed medicines $(p=0.01)$, >6 prescribed medicines $(p<0.001),>5$ days of hospital stay $(p=0.03)$, and diabetes mellitus $(p=0.04)$.

Conclusions: PDDIs are commonly observed in patients with malaria. Healthcare professional's knowledge about the most common pDDls could help in preventing pDDIs and their associated negative effects. Pertinent clinical parameters, such as laboratory findings and signs/symptoms need to be checked, particularly in patients with polypharmacy, longer hospital stay, and diabetes mellitus.
\end{abstract}

Keywords: Patient safety, Malaria, Clinical relevance, Potential drug-drug interactions, Polypharmacy

\section{Background}

Malaria is one of the infectious diseases that cause burden on the healthcare system. According to the latest World Health Organization (WHO) report released in

\footnotetext{
*Correspondence: ismailrph@uop.edu.pk
}

Department of Pharmacy, University of Peshawar, Khyber Pakhtunkhwa, Pakistan
2019, malaria accounts for 228 million cases worldwide in 2018 with an estimated number of deaths 405,000 [1]. In Pakistan, approximately 70,5000 cases of malaria have been reported in 2018 [2]. Worldwide, malaria remains one of the causes of death due to infectious diseases [3]. Population group that are more exposed to malaria include male gender, $>14$ years of age, and rural population [4].

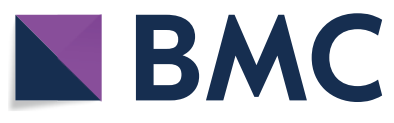

(c) The Author(s) 2020. This article is licensed under a Creative Commons Attribution 4.0 International License, which permits use, sharing, adaptation, distribution and reproduction in any medium or format, as long as you give appropriate credit to the original author(s) and the source, provide a link to the Creative Commons licence, and indicate if changes were made. The images or other third party material in this article are included in the article's Creative Commons licence, unless indicated otherwise in a credit line to the material. If material is not included in the article's Creative Commons licence and your intended use is not permitted by statutory regulation or exceeds the permitted use, you will need to obtain permission directly from the copyright holder. To view a copy of this licence, visit http://creativeco mmons.org/licenses/by/4.0/. The Creative Commons Public Domain Dedication waiver (http://creativecommons.org/publicdomain/ zero/1.0/) applies to the data made available in this article, unless otherwise stated in a credit line to the data. 
Hospitalization in malaria occurs due to disease severity, managing the associated symptoms or comorbid illnesses [5]. Anti-malarial drugs, anti-pyretic, and analgesics are usually prescribed to treat hospitalized malaria patients [6]. Besides these medicines, a variety of other medicines are also prescribed so as to manage the comorbid illnesses and associated symptoms [5-7]. Concomitant use of several drugs increased the chance of drug-drug interactions (DDIs)-affecting drug's pharmacokinetic parameters and pharmacodynamics profile $[8,9]$. DDIs may lead to a variety of negative clinical outcomes such as hospitalization, reduced or abolished therapeutic efficacy, prolongation of hospital stay, toxicity, and adverse effects [8-10]. An approximately, $20-30 \%$ of adverse effects have been reported as due to DDIs, of which $1-2 \%$ are life-threatening and $70 \%$ need clinical intervention [11]. Hence, particular consideration of DDIs and their timely management is crucial for the rational use of medicines in patients with malaria.

Potential DDIs (pDDIs) issue has been addressed generally in hospitalized patients [8] as well as in specific diseases such as liver cirrhosis [12], hypertension [13], diabetes mellitus (DM) [14], bone marrow transplant [15], cancer [16], stroke [17], pneumonia [18], urinary tract infections [19], and hepatitis C [20]. Despite, being one of the most prevalent causes of hospitalization in Pakistan during its emerging season [21]. DDIs particularly among inpatients with malaria remains unaddressed. Moreover, in developing countries, literature has been least reported as well as irrational use of medicines is a common issue. Consequently, specific consideration is required to conduct studies evaluating pDDIs and their clinical relevance among hospitalized patients with malaria. Afterward, such studies will improve patients' safety and help healthcare professionals to manage pDDIs and reduce their associated negative clinical consequences.

This study aimed to evaluate the prescriptions of inpatients with malaria for pDDIs prevalence, and their levels. Investigate the risk factors contributing towards pDDIs prevalence, and clinical relevance of pDDIs. Secondary aim was to identify monitoring parameters and develop management guidelines for the most frequent pDDIs.

\section{Methods}

\section{Study settings and design}

A retrospective cohort study was conducted at two tertiary care hospitals of Peshawar, Khyber Pakhtunkhwa, Pakistan such as Khyber Teaching Hospital (KTH) and Hayatabad Medical Complex (HMC). In healthcare system of Pakistan, tertiary care hospitals are more developed as compared to secondary or primary care hospitals. KTH and HMC are among the three major tertiary care hospitals where majority of the Khyber Pakhtunkhwa population visits for healthcare services. Malaria patients are more frequently observed in these two hospitals [4]. Malaria has been reported in high frequency in Peshawar in comparison to other cities of Khyber Pakhtunkhwa [22]. Plasmodium vivax and Plasmodium falciparum malaria are the common malaria forms found in these settings [4, 22]. Additionally, computerized drug interaction screening programmes and clinical pharmacy services are lacking in both the hospitals. Patient's profiles are developed in hand written format and records are maintained manually.

\section{Patient selection criteria}

Following were the inclusion criteria:

Patients diagnosed with malaria and hospitalized during 2-year period (from 01 January 2015 to 31 December 2016).

Patients aged $\geq 18$ years.

Both male or female patients.

All medications, that were prescribed during hospitalization of the patient were included in analysis.

A total of 409 malaria patients were hospitalized during study period. Eleven patients' profiles lacking relevant data (hospital admissions, patients' demographics, diagnoses, comorbidities/complications, medications therapy, sign/symptoms, daily progress reports, and laboratory test reports) required for the study were excluded.

\section{Sample size calculation and sampling technique}

Sample size was calculated by the following formula [23]:

$$
\mathrm{n}=\mathrm{Z}^{2} \mathrm{P}(1-\mathrm{P}) / \mathrm{d}^{2}
$$

Based on the above formula taking 52.8\% [21] of anticipated prevalence, $95 \%$ confidence level, and $5 \%$ margin of error, a sample size of 383 was obtained. Whereas, a total of 398 patients were eligible for inclusion in the study during the study period. Non-probability consecutive sampling technique was used for collecting data.

\section{Data source}

The following data were collected from the patients' profiles such as hospital admissions, patients' demographics, diagnoses, comorbidities/complications, medications therapy, sign/symptoms, and laboratory test reports.

\section{Medications profiles screening for $\mathrm{pDDls}$}

Medicines prescribed to patients were evaluated for pDDIs using Micromedex Drug-Reax ${ }^{\circledR}$ [24]. This software classifies drug interactions on the basis of 
severity- (contraindicated, major, moderate, and minor) and documentation-levels (excellent, good, and fair) [24]. Overall-prevalence of pDDIs as well as prevalence of pDDIs based on severity-levels were reported. Prevalence of pDDIs were explored by screening drug pairs per prescription.

\section{Clinical relevance}

The clinical relevance of ten most frequent pDDIs was reported, by correlating potential adverse consequences of pDDIs with patients' signs, symptoms and laboratory test results. The clinical manifestations were stratified based on dose differences of the interacting drugs. The following cut off points were used for defining higher daily doses, calcium containing products: $\geq 600 \mathrm{mg} / 3 \mathrm{~L}$; ceftriaxone: $\geq 3 \mathrm{~g}$; isoniazid: $\geq 300 \mathrm{mg}$; rifampin: $\geq 450 \mathrm{mg}$; pyrazinamide: $\geq 1500 \mathrm{mg}$; acetaminophen: $\geq 1$ g; prochlorperazine: $\geq 15 \mathrm{mg}$; quinine: $\geq 1350 \mathrm{mg}$; ranitidine: $\geq 150 \mathrm{mg}$; metronidazole: $\geq 1500 \mathrm{mg}$; domperidone: $\geq 30 \mathrm{mg}$; dexamethasone: $\geq 24 \mathrm{mg}$; and ciprofloxacin: $\geq 800 \mathrm{mg}$. Potential adverse effects in this study were defined based on Medscape laboratory reference ranges and Wiley standard laboratory values, which are as follow: leukocytosis: total leukocyte count $>11,000 / \mu \mathrm{L}$; elevated blood urea nitrogen (BUN): BUN $\leq 20 \mathrm{mg} / \mathrm{dL}$; elevated serum creatinine: serum creatinine $>1.06 \mathrm{mg} /$ $\mathrm{dL}$; elevated alkaline phosphatase: $>126 \mathrm{U} / \mathrm{L}$; elevated alanine aminotransferase: $>59 \mathrm{U} / \mathrm{L}$ (male), $>36 \mathrm{U} / \mathrm{L}$ (female); tachycardia: heart rate $>100$ beats $/ \mathrm{min}$; hypotension: systolic blood pressure $(\mathrm{BP})<80 \mathrm{mmHg}$ and/ or diastolic $\mathrm{BP}<50 \mathrm{mmHg}$; hypokalaemia: serum potassium <3.5 mmol/L. Management guidelines and monitoring parameters were developed for the most prevalent pDDIs. Widespread (most common) and clinically important pDDIs were enlisted along with their potential adverse consequences.

The causal association between the adverse outcomes and top-10 interacting drug combinations was evaluated through Drug Interaction Probability Scale (DIPS). It guides by using a series of 10 questions to calculate a probability score. According to DIPS, the DDIs induced adverse outcomes are categorized as highly probable ( $>8$ score), probable (5-8 score), possible ( $2-4$ score), or doubtful $(<2$ score $)[25,26]$.

\section{Statistical analysis}

Data were presented in the form of frequencies and percentages alone or with median and interquartile range (IQR), where appropriate. A statistical method of logistic regression analysis was used to calculate odds ratios (OR) for various risk factors of pDDIs such as patients' gender, age, number of prescribed medicines, hospital stay, and comorbidities. Dependent variable in the model was exposure to pDDIs. While, patients' characteristics (gender, age, number of prescribed medicines, hospital stay, and comorbidities) were taken as independent variables in the model. Odds ratios and 95\% confidence intervals (CIs) were calculated for each independent variable. Univariate logistic regression analysis was run initially. Then, multivariate analyses were performed for variables with $p$-values of $\leq 0.15$. A $p$-value of $\leq 0.05$ was considered as statistically significant. SPSS-v23 was used for statistical analyses of the data.

\section{Results}

\section{General characteristics of study patients}

Patients' demographics are presented in Table 1. Of 398 patients, males were more prevalent (51.8\%). Most of the patients were aged $21-40$ years (44.2\%). A majority of patients was prescribed with $\geq 5$ drugs $(80.4 \%)$. Most frequent hospital stay was $\geq 4$ days (64.6\%). The median (IQR) age, prescribed drugs and hospital stay was 30 years (22-50), 7 drugs (5-9), and 4 days (3-6), respectively. Hypertension $(\mathrm{n}=52), \mathrm{DM}(45)$, urinary tract infections (34), hepatitis (23), and ischemic heart diseases (IHD) (15) were the most prevalent comorbidities of the studied patients (Table 1). Of 398 patients, 8.3\% of the patients presented with falciparum malaria, $36.7 \%$ vivax malaria, while $55 \%$ were non-specific. While, $10.1 \%$ of the patients were presented with cerebral malaria one of the forms of severe/complicated malaria. Moreover, exposure to pDDIs stratified against the patient's characteristics are also shown in Table 1. PDDIs prevalence was found similar in male and female patients. While, pDDIs were commonly reported in patients aged $>40$ years, prescribed with $\geq 5$ medicines, and hospitalization of $>5$ days. Moreover, pDDIs were mostly reported in patients with DM and IHD as comorbidities.

\section{Prevalence of potential drug-drug interactions}

Out of total 398 patients, 148 (37.2\%) met at least one pDDI. Based on severity-wise prevalence, $19.3 \%$ patients were identified with at least one major-pDDI while, $15.8 \%$ with at least one moderate-pDDI. However, a smaller proportion of patients were found with contraindicated(14.3\%) and minor-pDDIs (1.3\%) (Fig. 1).

\section{Levels of potential drug-drug interactions}

Figure 2 illustrates categorization of pDDIs based on severity- and documentation-levels. Total number of interactions was 325, among which $45.5 \%$ were of major- and $34.5 \%$ moderate-severity. Based on documentation-levels, $49.5 \%$ were of fair and $44.9 \%$ good scientific-evidence. 
Table 1 General characteristics of study subjects and exposure to potential drug-drug interactions

\begin{tabular}{lll}
\hline General characteristics & Patients: $\mathbf{n}(\%)$ & $\begin{array}{l}\text { Exposure } \\
\text { to pDDls } \\
\\
\end{array}$ \\
& [Patients: $\mathbf{n}(\%)]$
\end{tabular}

\begin{tabular}{|c|c|c|}
\hline \multicolumn{3}{|l|}{ Gender } \\
\hline Male & $206(51.8)$ & $77(37.4)$ \\
\hline Female & $192(48.2)$ & $71(37)$ \\
\hline \multicolumn{3}{|l|}{ Age (years) } \\
\hline$\leq 20$ & $96(24.1)$ & $40(41.7)$ \\
\hline $21-40$ & $176(44.2)$ & $53(30.1)$ \\
\hline$>40$ & $126(31.7)$ & $55(43.7)$ \\
\hline Median (interquartile range) & $30(22-50)$ & \\
\hline \multicolumn{3}{|l|}{ Drugs prescribed } \\
\hline$<5$ & 78 (19.6) & $5(6.4)$ \\
\hline$\geq 5$ & $320(80.4)$ & $143(44.7)$ \\
\hline Median (interquartile range) & $7(5-9)$ & \\
\hline \multicolumn{3}{|l|}{ Hospital stay (days) } \\
\hline$\leq 3$ & $141(35.4)$ & $32(22.7)$ \\
\hline $4-5$ & $144(36.2)$ & $56(38.9)$ \\
\hline$>5$ & $113(28.4)$ & $60(53.1)$ \\
\hline Median (interquartile range) & $4(3-6)$ & \\
\hline \multicolumn{3}{|l|}{ Number of comorbidities } \\
\hline No comorbidities & $179(45)$ & - \\
\hline $1-2$ & $187(46.9)$ & - \\
\hline$\geq 3$ & $32(8)$ & - \\
\hline \multicolumn{3}{|l|}{ Comorbidities } \\
\hline Hypertension & $52(13.1)$ & $20(38.5)$ \\
\hline Diabetes mellitus & $45(11.3)$ & $27(60)$ \\
\hline Urinary tract infection & $34(8.5)$ & $13(38.2)$ \\
\hline Hepatitis & $23(5.8)$ & $11(47.8)$ \\
\hline Ischemic heart disease & $15(3.8)$ & $9(60)$ \\
\hline Anaemia & $13(3.3)$ & $3(23.1)$ \\
\hline Dengue fever & $12(3)$ & $5(41.7)$ \\
\hline Meningitis & $11(2.8)$ & $5(41.7)$ \\
\hline Respiratory tract infection & $9(2.3)$ & $2(22.2)$ \\
\hline Thrombocytopenia & $9(2.3)$ & $2(22.2)$ \\
\hline Typhoid & $9(2.3)$ & - \\
\hline Bicytopenia & $7(1.8)$ & - \\
\hline Acute gastroenteritis & $6(1.5)$ & - \\
\hline Asthma & $6(1.5)$ & - \\
\hline Tuberculosis & $6(1.5)$ & - \\
\hline Acute kidney injury & $5(1.3)$ & - \\
\hline Pancytopenia & $5(1.3)$ & - \\
\hline $\begin{array}{l}\text { Decompensated chronic liver } \\
\text { disease }\end{array}$ & $4(1)$ & - \\
\hline Pneumonia & $4(1)$ & - \\
\hline Congestive cardiac failure & $3(0.8)$ each & - \\
\hline Miscellaneous & $72(18)^{\mathrm{a}}$ & - \\
\hline
\end{tabular}

$p D D / s$ potential drug-drug interactions

a In miscellaneous the following diagnosis were reported: chronic obstructive pulmonary disease, depression, encephalitis, epilepsy, goiter, hepatic
Table 1 (continued)

encephalopathy, herpes labialis, post-natal endometriosis, thalassemia, deep vein thrombosis as $n=3(0.8 \%)$ each. While, cholelithiasis, fits, nephropathy, pleural effusion as $n=2(0.5 \%)$ each. However, achondroplasia, aortic stenosis, arthritis, atrial fibrillation, cellulitis, dementia, disseminated intravascular coagulation, down syndrome, endocarditis, eosinophilia, hyponatremia, hypothyroidism, immune thrombocytopenic purpura, leukemia, liver abscess, left ventricular failure, lymphoma, malignancy, menorrhagia, multiple myeloma, osteoporosis, post splenectomy, psychiatric disorder, rheumatic heart disease, renal tubular acidosis, systemic lupus erythematosus, spondylosis, sexually transmitted disease, stroke, thyrotoxicosis, tonsillitis, ulcerative colitis, urosepsis, Wilson disease as $\mathrm{n}=1(0.3 \%)$ each

\section{Risk factors of potential drug-drug interactions}

Table 2 shows logistic regression analysis based on exposure to pDDIs. In the univariate logistic regression analysis, association for pDDIs was statistically significant with $5-6$ prescribed medicines $(\mathrm{p}=0.005),>6$ prescribed medicines $(\mathrm{p}<0.001)$, hospital stay of $4-5$ days $(\mathrm{p}=0.003)$, and $>5$ days hospitalization $(\mathrm{p}<0.001)$. Moreover, concerning comorbidities, association of pDDIs with DM $(\mathrm{p}=0.001)$ and IHD $(\mathrm{p}=0.07)$ was statistically significant. In the multivariate logistic regression analysis, the association remained significant with $5-6$ prescribed medicines $(\mathrm{p}=0.01),>6$ prescribed medicines $(\mathrm{p}<0.001),>5$ days hospitalization $(\mathrm{p}=0.03)$, and $\mathrm{DM}(\mathrm{p}=0.04)$.

\section{Clinical relevance of potential drug-drug interactions}

Table 3 presents daily prescribed dosage of the ten most frequent interacting drug pairs. In this study, the term high and low doses were used relatively. It was observed that the drugs were prescribed in varying doses and administration frequencies. Interacting drugs were prescribed more frequently in low doses, whereas, higher doses of the drugs were prescribed less frequently. Most frequent pDDIs along with their frequencies, proportions, potential adverse consequences and severity- and documentation-levels are presented in Additional file 1: Table S1. Most of the top ten pDDIs were of major severity $(n=7)$. While Additional file 2: Table S2 and Additional file 3: Table S3 enlists most prevalent anti-microbial agents (AMAs) and drugs besides AMAs, respectively. Artesunate $(\mathrm{n}=378)$, quinine $(63)$, artemether (26), lumefantrine (23), primaquine (18), amodiaquine (11), and chloroquine (9) were the commonly prescribed anti-malarial agents to these study patients (Additional file 2: Table S2).

In Table 4, specific clinical features (signs, symptoms and/or laboratory findings) and management guidelines/monitoring parameters [24, 27] for ten most frequent pDDIs are reported. The clinical features were stratified based on dose differences of the interacting drug pairs. Signs, symptoms and abnormalities in laboratory findings indicating poor response and nephrotoxicity were detected in patients with the interaction, 


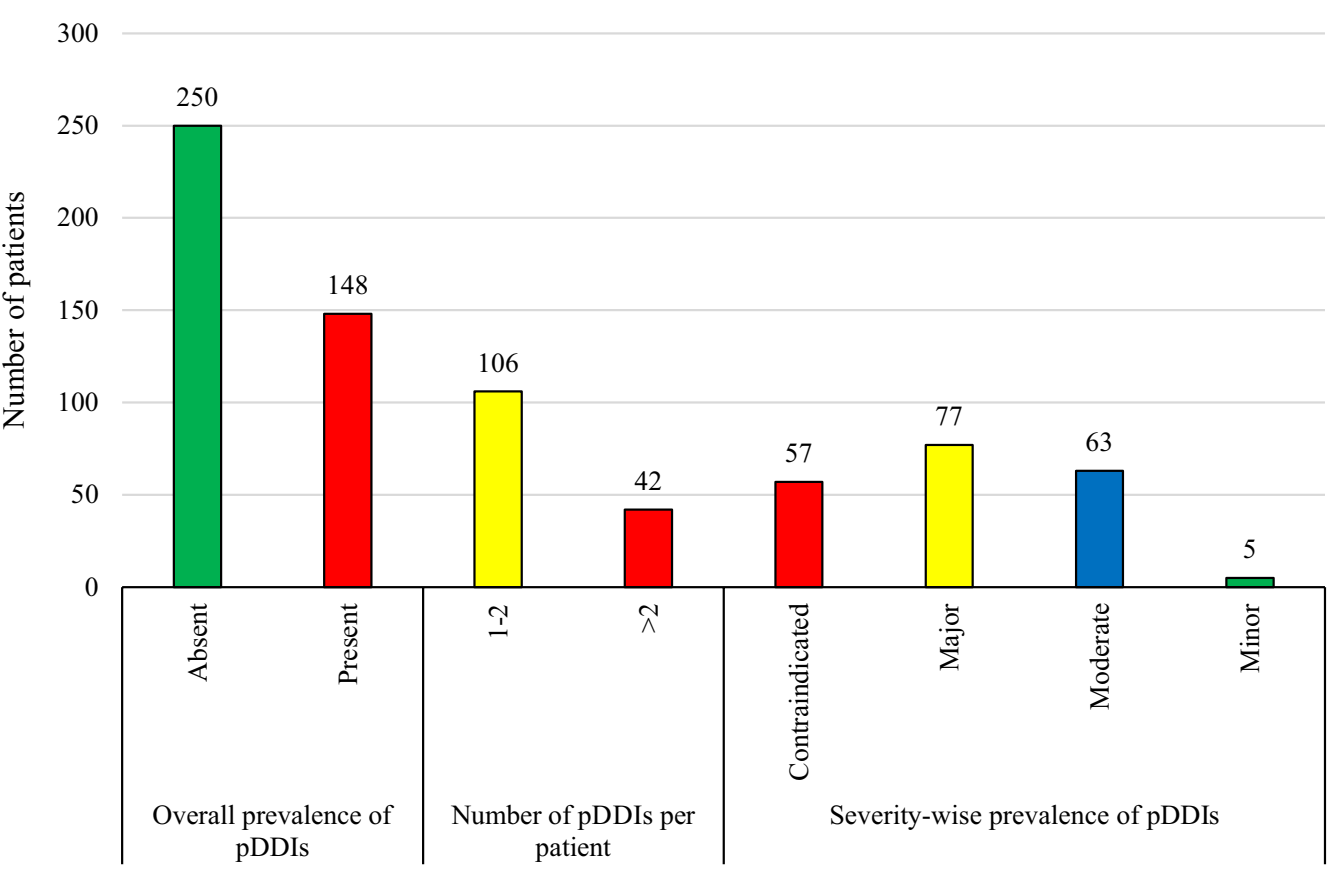

Fig. 1 Prevalence of potential drug-drug interactions. pDDls: potential drug-drug interactions. Data are presented in the form of frequencies. Overall-prevalence means the presence of at least one pDDI regardless of severity type. Study sample were 398 malaria patients. While, patients with pDDIs were 148 (overall prevalence of pDDIs $=37.2 \%$ ). PDDIs prevalence was also reported based on severity-levels

a

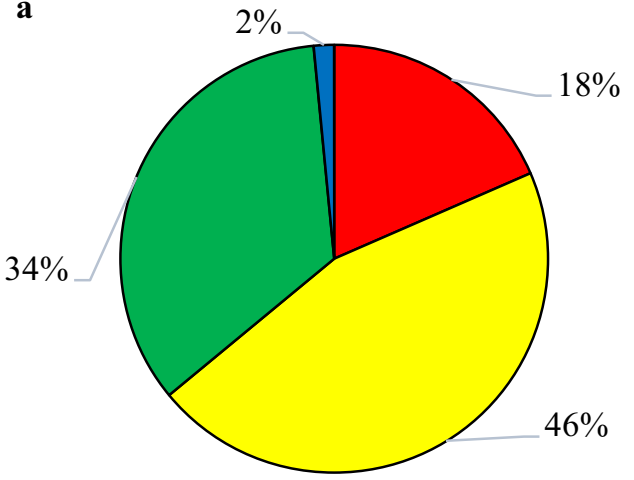

$\square$ Contraindicated $(\mathrm{n}=60)$

$\square$ Major $(\mathrm{n}=148)$

$\square$ Moderate $(\mathrm{n}=112)$

$\square \operatorname{Minor}(\mathrm{n}=5)$ b

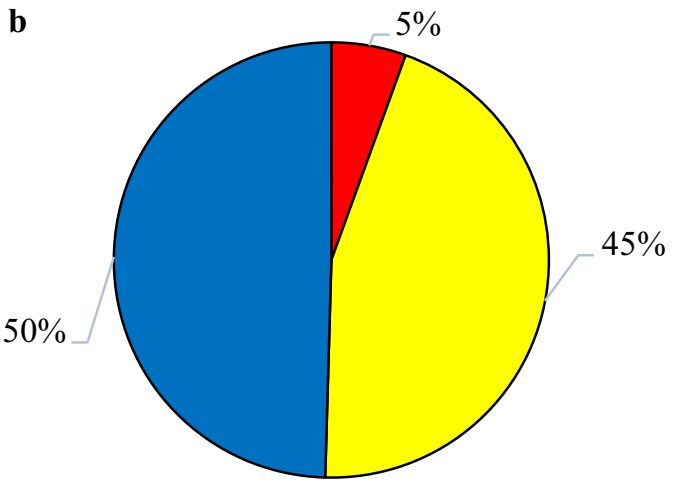

$\square$ Excellent $(\mathrm{n}=18)$

$\square \operatorname{Good}(\mathrm{n}=146)$

$\square$ Fair (n= 161)

Fig. 2 Levels of potential drug-drug interactions in patients with malaria. a Severity-levels of pDDIs. b Documentation-levels of pDDIs. pDDIs, potential drug-drug interactions. The total recorded pDDls 325 were classified based on severity-and documentation-levels

calcium containing products + ceftriaxone. Patients with the interactions pyrazinamide+rifampin, isoniazid + rifampin, and isoniazid + acetaminophen, were observed with the signs/symptoms of hepatotoxicity such as weight loss, anorexia, hepatomegaly, pale, weakness, body aches, and ascites, and abnormalities in 
Table 2 Logistic regression analysis based on exposure to potential drug-drug interactions

\begin{tabular}{|c|c|c|c|c|}
\hline \multirow[t]{2}{*}{ Variables } & \multicolumn{2}{|c|}{ Univariate analysis } & \multicolumn{2}{|c|}{ Multivariate analysis } \\
\hline & OR $(95 \% \mathrm{Cl})$ & $p$-value & OR $(95 \% \mathrm{Cl})$ & $p$-value \\
\hline \multicolumn{5}{|l|}{ Gender } \\
\hline Female & Reference & & - & \\
\hline Male & $1(0.7-1.5)$ & 0.9 & - & - \\
\hline \multicolumn{5}{|l|}{ Age (years) } \\
\hline$\leq 20$ & Reference & & Reference & \\
\hline $21-40$ & $0.6(0.4-1)$ & 0.05 & $0.6(0.3-1.1)$ & 0.1 \\
\hline$>40$ & $1.1(0.6-1.9)$ & 0.8 & $0.6(0.3-1.1)$ & 0.1 \\
\hline \multicolumn{5}{|l|}{ Drugs prescribed } \\
\hline$\leq 4$ & Reference & & Reference & \\
\hline $5-6$ & $4.3(1.5-11.8)$ & 0.005 & $3.9(1.4-10.8)$ & 0.01 \\
\hline$>6$ & $17.9(6.9-45.9)$ & $<0.001$ & $14.1(5.4-37.3)$ & $<0.001$ \\
\hline \multicolumn{5}{|l|}{ Hospital stay (days) } \\
\hline$\leq 3$ & Reference & & Reference & \\
\hline $4-5$ & $2.2(1.3-3.6)$ & 0.003 & $1.5(0.8-2.6)$ & 0.2 \\
\hline$>5$ & $3.9(2.2-6.6)$ & $<0.001$ & $1.9(1.1-3.5)$ & 0.03 \\
\hline \multicolumn{5}{|l|}{ Comorbidities } \\
\hline Hypertension & $1.1(0.6-1.9)$ & 0.8 & - & - \\
\hline Diabetes mellitus & $2.9(1.5-5.4)$ & 0.001 & $2.2(1-4.8)$ & 0.04 \\
\hline Urinary tract infection & $1.1(0.5-2.2)$ & 0.9 & - & - \\
\hline Hepatitis & $1.6(0.7-3.7)$ & 0.3 & - & - \\
\hline Ischemic heart disease & $2.6(0.9-7.6)$ & 0.07 & $2.4(0.7-8.5)$ & 0.2 \\
\hline Anaemia & $0.5(0.1-1.8)$ & 0.3 & - & - \\
\hline Dengue fever & $1.2(0.4-3.9)$ & 0.7 & - & - \\
\hline Meningitis & $1.4(0.4-4.7)$ & 0.6 & - & - \\
\hline Respiratory tract infection & $0.5(0.09-2.3)$ & 0.4 & - & - \\
\hline Thrombocytopenia & $0.5(0.09-2.3)$ & 0.4 & - & - \\
\hline
\end{tabular}

$\mathrm{Cl}$ confidence interval, $\mathrm{OR}$ odds ratio

laboratory tests, such as elevated alkaline phosphatase and elevated alanine aminotransferase. Patients with the interacting pair, prochlorperazine + quinine, metronidazole + quinine, domperidone + ranitidine, and ciprofloxacin + metronidazole, were observed with clinical features and abnormalities in laboratory tests suggesting QT interval prolongation. Clinical features suggesting poor response of the drugs were observed in patients with the interacting pairs cefpodoxime + ranitidine and dexamethasone + rifampin. Table 4 further enlists monitoring parameters and management guidelines specifically for each interacting pair. Adverse consequences for the most frequent pDDIs were nephrotoxicity, hepatotoxicity, QT interval prolongation, and decreased therapeutic response. In general, monitoring parameters for the associated adverse effects includes related signs/symptoms and abnormal laboratory findings such as liver function tests, ECG, and renal function tests. Most of these associated adverse consequences can be managed by discontinuing the combination or adjusting the dose.
According to DIPS, pDDIs with a score of 5 (probable) were observed in the following drug combinations: calcium containing products-ceftriaxone $(\mathrm{n}=28$; $53.8 \%)$, isoniazid-rifampin $(\mathrm{n}=4 ; 40 \%)$, pyrazinamide-rifampin $(n=6 ; 60 \%)$, isoniazid-acetaminophen $(n=6 ; 66 \%)$, prochlorperazine-quinine $(n=5 ; 62 \%)$, cefpodoxime-ranitidine $(\mathrm{n}=3 ; 42.9 \%)$, metronidazolequinine $(n=3 ; 50 \%)$, domperidone-ranitidine $(n=3$; $50 \%)$, dexamethasone-rifampin $(\mathrm{n}=1 ; 20 \%)$, and ciprofloxacin-metronidazole $(\mathrm{n}=2 ; 40 \%)$. While, the following interacting pairs were observed with a score of 6 (probable): calcium containing products-ceftriaxone $(n=16 ; 30.8 \%)$, isoniazid-rifampin $(n=3 ; 30 \%)$, pyrazinamide-rifampin $(\mathrm{n}=2 ; 20 \%)$, isoniazid-acetaminophen $(\mathrm{n}=2 ; 22 \%)$, cefpodoxime-ranitidine $(\mathrm{n}=2$; $28.6 \%)$, metronidazole-quinine $(n=1 ; 16.7 \%)$, domperidone-ranitidine $(\mathrm{n}=1 ; 16.7 \%)$, dexamethasonerifampin $(n=3 ; 60 \%)$, and ciprofloxacin-metronidazole $(n=3 ; 60 \%)$. 
Table 3 Dose regimen of the prescribed interacting drugs

\begin{tabular}{|c|c|c|c|}
\hline Interacting pair & Dose categories $^{\mathrm{a}}$ & Daily prescribed dose regimen & $\begin{array}{l}\text { Number } \\
\text { of patients }\end{array}$ \\
\hline \multirow[t]{13}{*}{ Calcium containing products_-Ceftriaxone } & Low+low & 200 mg/L OD + 2 g OD ATD & 10 \\
\hline & Low + low & 200 mg/L BD + 2 g OD ATD & 9 \\
\hline & Low+low & 200 mg/L BD + 1 g BD ATD & 8 \\
\hline & Low + high & 200 mg/L OD + 2 g BD ATD & 6 \\
\hline & Low + high & 200 mg/L BD + 2 g BD ATD & 5 \\
\hline & High + high & 200 mg/L TDS + 2 g BD ATD & 3 \\
\hline & High + low & 200 mg/L TDS + 2 g OD ATD & 3 \\
\hline & Low + high & 200 mg/L OD + 3 g OD ATD & 2 \\
\hline & High + low & $1 \mathrm{~g} \mathrm{OD}+2 \mathrm{~g}$ OD ATD & 2 \\
\hline & Low + high & 200 mg/L BD + 3 g OD ATD & 1 \\
\hline & Low + high & $200 \mathrm{mg} / \mathrm{L} \mathrm{BD}+4 \mathrm{~g}$ OD ATD & 1 \\
\hline & High + high & $1 \mathrm{~g} \mathrm{OD}+2 \mathrm{~g} \mathrm{BD} \mathrm{ATD}$ & 1 \\
\hline & Low + low & 200 mg/L OD + 1 g OD ATD & 1 \\
\hline \multirow[t]{3}{*}{ Isoniazid-rifampin } & High + high & 300 mg OD + 600 mg OD & 6 \\
\hline & Low + high & $225 \mathrm{mg} O \mathrm{OD}+450 \mathrm{mg} \mathrm{OD}$ & 2 \\
\hline & Low+low & 150 mg OD + 300 mg OD & 2 \\
\hline \multirow[t]{3}{*}{ Pyrazinamide-rifampin } & High + high & $1600 \mathrm{mg} O D+600$ mg OD & 6 \\
\hline & Low + high & $1200 \mathrm{mg} O \mathrm{OD}+450 \mathrm{mg} \mathrm{OD}$ & 2 \\
\hline & High + low & 500 mg TDS + 300 mg OD & 2 \\
\hline \multirow[t]{6}{*}{ Isoniazid-acetaminophen } & High + high & $300 \mathrm{mg}$ OD + $500 \mathrm{mg}$ TDS & 2 \\
\hline & Low + high & $300 \mathrm{mg}$ OD + $500 \mathrm{mg}$ TDS & 2 \\
\hline & High + high & $300 \mathrm{mg} O D+1 \mathrm{~g} O D$ & 2 \\
\hline & Low+low & 150 mg OD + 300 mg OD & 1 \\
\hline & Low + high & $150 \mathrm{mg}$ OD + $500 \mathrm{mg}$ TDS & 1 \\
\hline & High + high & 300 mg OD + 500 mg QID & 1 \\
\hline \multirow[t]{4}{*}{ Prochlorperazine-quinine } & High + high & $5 \mathrm{mg}$ TDS + $600 \mathrm{mg}$ TDS & 4 \\
\hline & Low+low & $5 \mathrm{mg} \mathrm{BD}+600 \mathrm{mg} \mathrm{BD}$ & 2 \\
\hline & High + high & $5 \mathrm{mg}$ TDS + $450 \mathrm{mg}$ TDS & 1 \\
\hline & High + low & $5 \mathrm{mg}$ TDS + $300 \mathrm{mg}$ TDS & 1 \\
\hline \multirow[t]{2}{*}{ Cefpodoxime-ranitidine } & Low+low & 100 mg BD + 50 mg BD & 5 \\
\hline & Low + high & 100 mg BD + 50 mg TDS & 2 \\
\hline \multirow[t]{2}{*}{ Metronidazole-quinine } & High + high & $500 \mathrm{mg}$ TDS + $600 \mathrm{mg}$ TDS & 5 \\
\hline & Low + low & 400 mg TDS + 600 mg BD & 1 \\
\hline \multirow[t]{3}{*}{ Domperidone-ranitidine } & High + low & 10 mg TDS + 50 mg BD & 4 \\
\hline & Low + high & $10 \mathrm{mg} \mathrm{BD}+50 \mathrm{mg}$ TDS & 1 \\
\hline & High + high & $10 \mathrm{mg}$ TDS + $50 \mathrm{mg}$ TDS & 1 \\
\hline \multirow[t]{3}{*}{ Dexamethasone-rifampin } & High + high & $8 \mathrm{mg}$ TDS +600 mg OD & 3 \\
\hline & Low + high & $8 \mathrm{mg} \mathrm{BD}+600$ mg OD & 1 \\
\hline & Low+ low & 4 mg TDS + 450 mg OD & 1 \\
\hline \multirow[t]{3}{*}{ Ciprofloxacin-metronidazole } & High + low & $500 \mathrm{mg} \mathrm{BD}+500 \mathrm{mg}$ TDS & 3 \\
\hline & High + low & $400 \mathrm{mg} \mathrm{BD}+500 \mathrm{mg}$ TDS & 1 \\
\hline & Low+low & $250 \mathrm{mg} \mathrm{BD}+500 \mathrm{mg}$ TDS & 1 \\
\hline
\end{tabular}

$O D$ once a day, $B D$ twice a day, QID four times a day, TDS three times a day, ATD alternate day

a The terms low and high doses were used relatively. For defining higher daily doses the following cut off points were used, calcium containing products: $\geq 600 \mathrm{mg} / 3$ L; ceftriaxone: $\geq 3 \mathrm{~g}$; isoniazid: $\geq 300 \mathrm{mg}$; rifampin: $\geq 450 \mathrm{mg}$; pyrazinamide: $\geq 1500 \mathrm{mg}$; acetaminophen: $\geq 1$ g; prochlorperazine: $\geq 15 \mathrm{mg}$; quinine: $\geq 1350 \mathrm{mg}$; ranitidine: $\geq 150 \mathrm{mg}$; metronidazole: $\geq 1500 \mathrm{mg}$; domperidone: $\geq 30 \mathrm{mg}$; dexamethasone: $\geq 24 \mathrm{mg}$; and ciprofloxacin: $\geq 800 \mathrm{mg}$ 


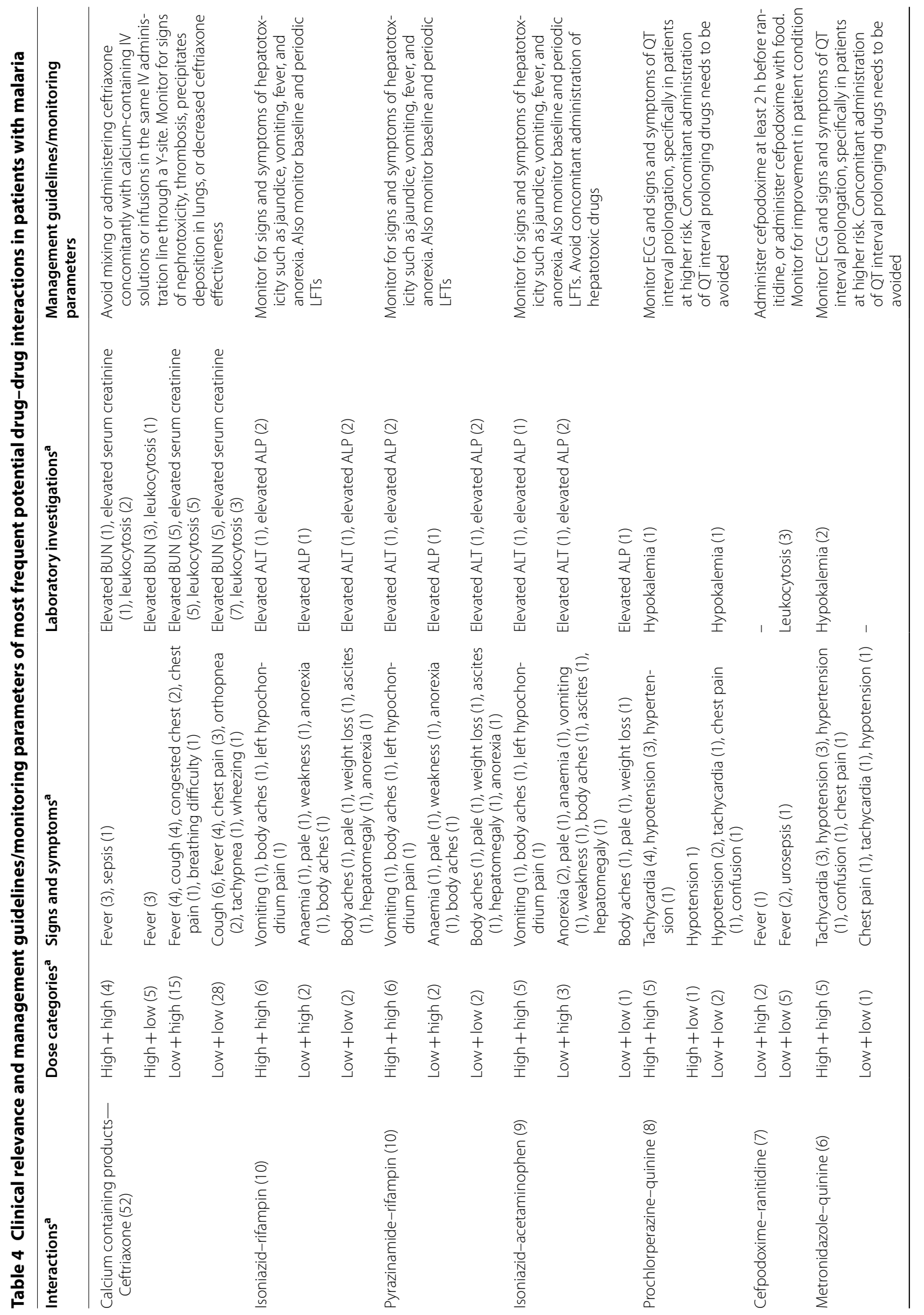




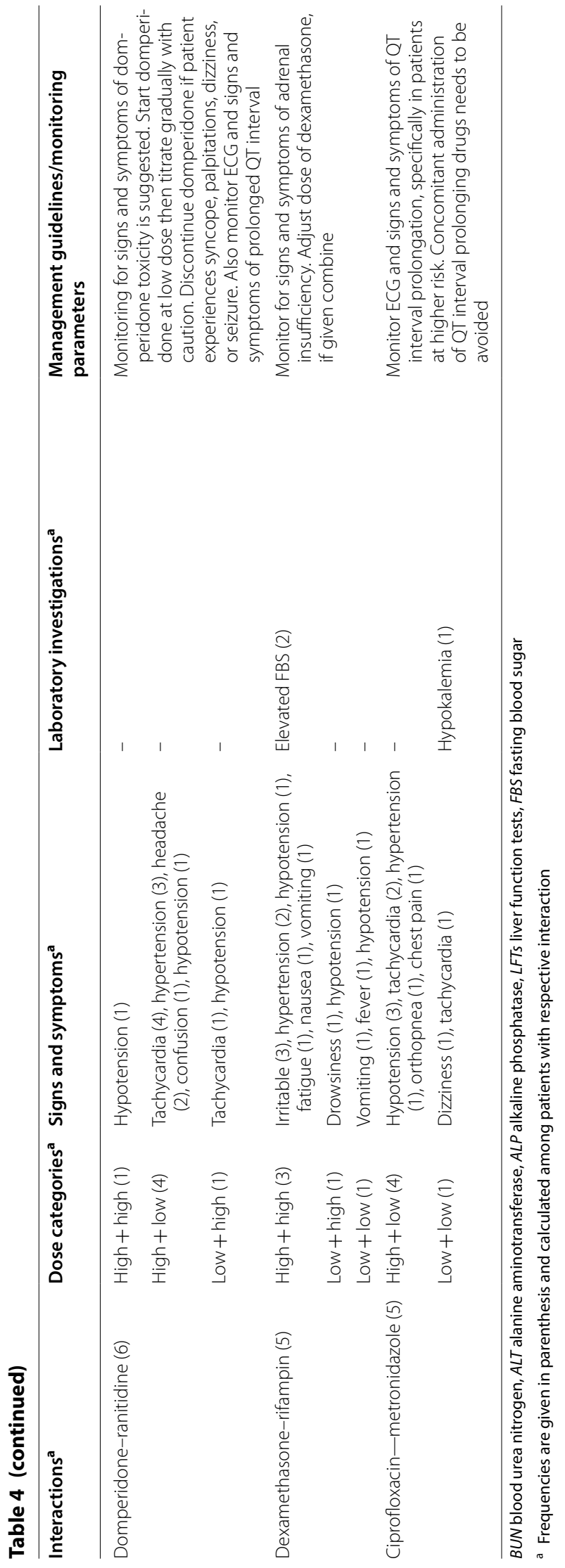




\section{Discussion}

DDIs remains one of the therapeutic challenges among inpatients [8]. Studies addressing pDDIs issues among hospitalized patients with malaria are lacking. The prevalence of pDDIs reported in the current research is higher (37.2\%) in comparison to that among patients with acquired immune deficiency (33.5\%) [28], liver cirrhosis (21.5\%) [12], and hypertension (21.1\%) [13]. Contrary, it is lower (37.2\%) as compared to that among patients with hypertension (48\%) [29], DM (52.2\%) [14], and bone marrow transplant (60\%) [15]. Furthermore, in current study, prevalence of major-pDDIs is higher (19.3\%) as compared to that reported among patients with cancer (16\%) [16]. Whereas, it is lower in comparison to that reported among patients with liver cirrhosis (21.4\%) [12], hepatitis C (30-44\%) [20], and stroke (61\%) [17]. Similarly, the prevalence of contraindicated-pDDIs in patients with malaria is also lower (14.3\%) in comparison to the prevalence reported among patients with hepatitis $C(16.7 \%)$ [30]. This contradiction may be due to variable study population, drug prescribing patterns, study design, considering pDDIs types, and drug interaction screening software. Considering the findings of this study, malaria patients are more at risk to pDDIs. Further, $36.7 \%$ of the study patients were presented with vivax malaria and 8.3\% falciparum malaria and $10.1 \%$ were diagnosed as cerebral malaria. These findings showed that patients of the current study were severely ill and DDIs can further deteriorate patients' condition. Published literature has proposed some evidence based approaches to minimize, prevent or manage DDIs in hospital settings, such as screening medication profiles for pDDIs by using computerized screening programmes [31], engaging clinical pharmacists in assessing patients' medication profiles for pDDIs [32-34], procedure for structured assessment of pDDIs [35], and checking pertinent laboratory findings for clinical relevance of interactions $[8,36]$.

Healthcare professionals can manage adverse outcomes related to interactions, by taking into considerations the levels of interactions. In this study, pDDIs of major and moderate types were commonly observed, while concerning documentation levels, pDDIs of fair and good types were more prevalent. These findings are inconsistent with the findings from other studies [12, 21, 37]. This situation is alarming as the findings of this study warrant about the exposure of malaria patients towards negative consequences of pDDIs. Therefore, identifying the type of interaction, by healthcare professional is crucial for managing pDDIs, minimizing the related risk, and designing prophylactic measures for prevention.

Hospitalized patients with malaria receive a variety of medications for the management of underlying disease, related complications, and/or comorbid illnesses [5-7].
The findings of this study support that provision of multiple therapy has been positively associated with pDDIs prevalence [16, 37-39]. Moreover, the statistically significant association of pDDIs with prolong hospitalization reported by the current study is in accordance with the published reports [21, 40]. Furthermore, this study observed a significant association of pDDIs with DM as comorbidity of malaria. The reason is that, in patients with DM, such drugs are prescribed, having higher risk of DDIs [41]. Furthermore, most commonly prescribed antimalarials agents in our study patients were artesunate, quinine, artemether, lumefantrine, primaquine, amodiaquine, and chloroquine. While, quinine, artemether and lumefantrine were involved in most frequent pDDIs (Additional file 1: Table S1). Therefore, malarial patients to whom these drugs are prescribed must be screened for DDIs. In this regard, hospitalized malaria patients having any of the above-mentioned risk factors are at higher risk to pDDIs. Healthcare professionals should have knowledge regarding the factors contributing towards pDDIs prevalence. This will help in reducing the risk of pDDIspatients more at risk to pDDIs should be individualized to improve drug therapy and reduce the adverse outcomes of pDDIs.

All types of pDDIs are not clinically significant. Hence, developing the list of clinically significant DDIs of the drugs used by patients with malaria is of immense need. The list will be helpful for the healthcare professionals for selective screening and identification of DDIs. Further, physician's understanding and knowledge of DDIs helps in reducing the occurrence of associated adverse effects, providing quality care, adjusting therapeutic regimen, and avoiding related medicolegal concerns. Moreover, the frequently identified pDDIs may results in serious adverse outcomes such as hepatotoxicity, QT interval prolongation, hypoglycaemia, hyperglycaemia, bleeding, hypertension, reduction in therapeutic effectiveness, and drug's toxicity. This is of particular concern because of associated risk of harm to patient.

A particular strength of this study is the assessment of clinical relevance of pDDIs. A limited number of studies focused on such an evaluation. Clinical relevance presents possible consequences of DDIs on clinical indicators/features and laboratory findings. In addition, clinical relevance also highlights the importance of screening medication list for DDIs-enlightened by published literature [32, 36, 39]. Assessing patients' abnormal signs/ symptoms and laboratory investigations help in monitoring the adverse consequences associated with DDIs. The potential negative consequences of ten most frequent pDDIs, observed in this study and published reports, emphasis the need of monitoring patients using these combinations $[10,42,43]$. In this study, doses of the 
interacting drugs have also been considered. Relatively higher doses of the interacting drugs may potentiate the harmful effects of the DDIs. This report showed that adverse effects were commonly observed among patients with higher doses of the interacting drugs. Adverse consequences related to DDIs can be reduced by checking patients' clinical manifestations and laboratory reports. In this study, most of the pDDIs have a DIPS of 5 or 6 , which means adverse effects were probably associated with the DDIs. DDIs with a high percentage of DIPS were more likely involved in clinically relevant interactions and adverse outcomes. Causality analysis of adverse events with DDIs will help in finding the cause of DDIs and managing the adverse effects. Thus, this aspect of therapy needs appropriate attention. Furthermore, monitoring parameters and/management guidelines for DDIs will be helpful for healthcare professionals to assess and manage DDIs in malaria patients. Additionally, this study can be extrapolated to other malarial patients hospitalized in Pakistani as well as other countries setup except those countries having variable malaria types and prescribing pattern $[44,45]$. The diverse comorbidity profile [46], disease pattern [22, 47], and similar malaria type and prescribing pattern [46-48] will results in almost similar prevalence of pDDIs. A large amount of data was collected from two hospitals-which are major tertiary care hospitals of the Province receiving maximum number of patients from whole of the Province.

Potential limitations of this study include inclusion of inpatients. As in hospitals, patients with malaria are chiefly admitted for the treatment of related signs/symptoms/complications or various comorbid illnesses. The pDDIs identified in this study are primarily associated with the use of medications for the management of such issues. Therefore, the findings of this study may not be generalizable to ambulatory patients in whom the drug utilization, drug interaction, and disease pattern possibly are different. Moreover, in the current study, the term pDDIs has been used as; DDIs were not actually observed. If such assessment, is made prospectively it will have positive clinical outcomes. Data are scarce regarding adverse clinical outcomes produced by drug interactions. However, in published literature some retrospective studies are available highlighting the importance of such an evaluation $[9,49]$.

\section{Conclusions}

PDDIs are commonly observed in patients with malaria due to prescription of drugs having higher risk of pDDIs. Healthcare professional's knowledge about the most common pDDIs could help in preventing pDDIs and their associated negative effects. Pertinent clinical parameters, such as laboratory findings and signs/symptoms need to be checked, particularly in patients with polypharmacy, longer hospital stay, and diabetes mellitus. Careful monitoring for adverse outcomes as well as prescribing drugs with a low risk for pDDIs are significant measures to decrease adverse effects associated with DDIs.

\section{Supplementary information}

Supplementary information accompanies this paper at https://doi. org/10.1186/s12936-020-03392-5.

Additional file 1: Table S1. Description of the most frequent potential drug-drug interactions in patients with malaria.

Additional file 2: Table S2. Most frequently prescribed antimicrobial agents among patient with malaria.

Additional file 3: Table S3. Most frequently prescribed drugs (other than antimicrobials) among patient with malaria.

\section{Abbreviations}

AMAs: Antimicrobial agents; ALP: Alkaline phosphatase; ATD: Alternate day; ALT: Alanine aminotransferase; BD: Twice a day; BP: Blood pressure; BUN: Blood urea nitrogen; $\mathrm{Cl}$ : Confidence interval; DDIs: Drug-drug interactions; DM: Diabetes mellitus; FBS: Fasting blood sugar; IHD: Ischemic heart diseases; IQR: Interquartile range; LFTs: Liver function tests; OD: Once a day; OR: Odds ratios; pDDIs: Potential drug-drug interactions; QID: Four times a day; TDS: Three times a day.

\section{Acknowledgements}

We are very thankful for the cooperation of staff and administration of the hospitals.

\section{Authors' contributions}

All the authors contributed substantially to the work presented in this paper. SN designed all the work under the supervision of MI, collected, analysed and interpreted data, did DDIs screening, drafted the manuscript. MI designed the research, contributed substantially with data analysis, results interpretations and manuscript editing and approval. FK collected, analysed and interpreted data, did DDIs screening, drafted the manuscript. All authors read and approved the final manuscript.

Funding

No funding has been taken for this study.

Availability of data and materials

The datasets used and/or analysed during the current study are available from the corresponding author on reasonable request.

Ethics approval and consent to participate

Institutional Research and Ethics Board of Postgraduate Medical Institute, Peshawar, provided ethics approval (Reference number: 15442). This study contains data obtained from the hospital record, therefore informed consent from the patients was not applicable.

\section{Consent for publication}

Not applicable.

Competing interests

The authors declare that they have no competing interests.

Received: 12 June 2020 Accepted: 25 August 2020

Published online: 31 August 2020 


\section{References}

1. WHO. Malaria. Geneva: World Health Organization. https://www.who.int/ news-room/fact-sheets/detail/malaria\#: :text=Malaria\%20is\%20a\%20 life\%2Dthreatening,at\%20405\%20000\%20in\%202018. Accessed 27 July 2020.

2. WHO. World malaria report 2019. Geneva: World Health Organization; 2019. https://www.who.int/malaria/publications/world-malaria-repor t-2019/en/. Accessed 27 July 2020.

3. Dye C. After 2015: infectious diseases in a new era of health and development. Philos Trans R Soc Lond B Biol Sci. 2014;369:20130426.

4. Khan AM, Hassan A, Ullah I, Din AU, Hayat A. The frequency of malaria in patients visiting selected hospitals in Peshawar, Khyber Pakhtunkhwa, Pakistan. J Entomol Zool Stud. 2018;6:2277-83.

5. Zubairi AB, Nizami S, Raza A, Mehraj V, Rasheed AF, Ghanchi NK, et al. Severe Plasmodium vivax malaria in Pakistan. Emerg Infect Dis. 2013;19:1851-4

6. Dodoo AN, Fogg C, Asiimwe A, Nartey ET, Kodua A, Tenkorang O, et al Pattern of drug utilization for treatment of uncomplicated malaria in urban Ghana following national treatment policy change to artemisinincombination therapy. Malar J. 2009:8:2

7. Bassi PU, Osakwe Al, Ogar CK, Elagbaje C, Nwankwo BB, Balogun ST, et al. Impact of comorbidity on adverse drug reaction profile in a cohort of patients treated with artemisinin combination therapies for uncomplicated malaria in Nigeria. Pharmacol Res Perspect. 2017;5:e00302.

8. Zwart-van-Rijkom JE, Uijtendaal EV, Ten-Berg MJ, Van-Solinge WW, Egberts AC. Frequency and nature of drug-drug interactions in a Dutch university hospital. Br J Clin Pharmacol. 2009;68:187-93.

9. Juurlink DN, Mamdani M, Kopp A, Laupacis A, Redelmeier DA. Drug-drug interactions among elderly patients hospitalized for drug toxicity. JAMA. 2013;289:1652-8.

10. Khan Q, Ismail M, Haider I, Haq IU, Noor S. QT interval prolongation in hospitalized patients on cardiology wards: a prospective observational study. Eur J Clin Pharmacol. 2017;73:1511-8.

11. Kohler Gl, Bode-Boger SM, Busse R, Hoopmann M, Welte T, Boger $\mathrm{RH}$. Drug-drug interactions in medical patients: effects of in-hospital treatment and relation to multiple drug use. Int J Clin Pharmacol Ther 2000;38:504-13.

12. Franz CC, Egger S, Born C, Bravo AER, Krahenbuhl S. Potential drug-drug interactions and adverse drug reactions in patients with liver cirrhosis. Eur J Clin Pharmacol. 2012;68:179-88.

13. Sivva D, Mateti UV, Neerati VM, Thiruthopu NS, Martha S. Assessment of drug-drug interactions in hypertensive patients at a superspeciality hospital. Avicenna J Med. 2015;5:29-35.

14. Dinesh KU, Subish P, Pranaya M, Shankar PR, Anil SK, Durga B. Pattern of potential drug-drug interactions in diabetic out-patients in a tertiary care teaching hospital in Nepal. Med J Malaysia. 2007:62:294-8.

15. Guastaldi RB, Reis AM, Figueras A, Secoli SR. Prevalence of potential drugdrug interactions in bone marrow transplant patients. Int J Clin Pharm. 2011:33:1002-9.

16. Van Leeuwen RW, Brundel DH, Neef C, van Gelder T, Mathijssen RH, Burger DM, et al. Prevalence of potential drug-drug interactions in cancer patients treated with oral anticancer drugs. Br J Cancer. 2013;108:1071-8.

17. Caratozzolo S, Gipponi S, Marengoni A, Pari E, Scalvini A, Pasina L, et al. Potentially serious drug-drug interactions in older patients hospitalized for acute ischemic and hemorrhagic stroke. Eur Neurol. 2016;76:161-6.

18. Noor S, Ismail M, Ali Z. Potential drug-drug interactions among pneumonia patients: do these matter in clinical perspectives? BMC Pharmacol Toxicol. 2019;20:45.

19. Noor S, Ismail M, Khan F. Potential drug-drug interactions in patients with urinary tract infections: a contributing factor in patient and medication safety. Front Pharmacol. 2019;10:1032.

20. Kondili LA, Gaeta GB, leluzzi D, Zignego AL, Monti M, Gori A, et al. Real-life data on potential drug-drug interactions in patients with chronic hepatitis $C$ viral infection undergoing antiviral therapy with interferon-free DAAs in the PITER Cohort Study. PLoS ONE. 2017;12:e0172159.

21. Ismail M, Iqbal Z, Khattak MB, Khan MI, Arsalan H, Javaid A, et al. Potential drug-drug interactions in internal medicine wards in hospital setting in Pakistan. Int J Clin Pharm. 2013;35:455-62.

22. Khattak AA, Venkatesan M, Nadeem MF, Satti HS, Yaqoob A, Strauss K, et al. Prevalence and distribution of human Plasmodium infection in Pakistan. Malar J. 2013;12:297.
23. Daniel WW, Cross CL. Biostatistics: a foundation for analysis in the health sciences. 10th ed. New York: John Wiley \& Sons; 2013.

24. Micromedex Drug-Reax ${ }^{\circledR}$, Greenwood Village, CO: Truven Health Analytics. https://www.micromedexsolutions.com/home/dispatch/ssl/true. Accessed Oct 202017

25. Horn JR, Hansten PD, Chan LN. Proposal for a new tool to evaluate drug interaction cases. Ann Pharmacother. 2007;41:674-80.

26. Muhič N, Mrhar A, Brvar M. Comparative analysis of three drug-drug interaction screening systems against probable clinically relevant drugdrug interactions: a prospective cohort study. Eur J Clin Pharmacol. 2017;73:875-82.

27. Baxter K. Stockley's interactions. 9th ed. London: Pharmaceutical Press; 2010.

28. Kigen G, Kimaiyo S, Nyandiko W, Faragher B, Sang E, Jakait B, et al. Prevalence of potential drug-drug interactions involving antiretroviral drugs in a large kenyan cohort. PLoS ONE. 2011;6:e16800.

29. Subramanian A, Adhimoolam M, Kannan S. Study of drug-Drug interactions among the hypertensive patients in a tertiary care teaching hospital. Perspect Clin Res. 2018;9:9-14.

30. Patel N, Nasiri M, Koroglu A, Bliss S, Davis M, McNutt LA, et al. A crosssectional study comparing the frequency of drug interactions after adding simeprevir-or sofosbuvir-containing therapy to medication profiles of hepatitis C monoinfected patients. Infect Dis Ther. 2015;4:67-78.

31. Moura CS, Prado NM, Belo NO, Acurcio FA. Evaluation of drug-drug interaction screening software combined with pharmacist intervention. Int J Clin Pharm. 2012;34:547-52.

32. Vonbach $\mathrm{P}$, Dubied $\mathrm{A}$, Beer $\mathrm{JH}$, Krahenbuhl S. Recognition and management of potential drug-drug interactions in patients on internal medicine wards. Eur J Clin Pharmacol. 2007;63:1075-83.

33. Langness JA, Nguyen M, Wieland A, Everson GT, Kiser JJ. Optimizing hepatitis $C$ virus treatment through pharmacist interventions: identification and management of drug-drug interactions. World J Gastroenterol. 2017;23:1618-26.

34. Hahn M, Reiff J, Hiemke C, Braus DF. Drug-drug-interactions in psychiatry. Psychiatr Prax. 2013;40:154-8.

35. Van Roon EN, Flikweert S, le Comte M, Langendijk PN, Kwee-Zuiderwijk WJ, Smits $\mathrm{P}$, et al. Clinical relevance of drug-drug interactions: a structured assessment procedure. Drug Saf. 2005:28:1131-9.

36. Geerts AF, De-Koning FH, De-Smet PA, Van-Solinge WW, Egberts TC. Laboratory tests in the clinical risk management of potential drug-drug interactions: a cross-sectional study using drug-dispensing data from 100 Dutch community pharmacies. Drug Saf. 2009;32:1189-97.

37. Murtaza G, Khan MY, Azhar S, Khan SA, Khan TM. Assessment of potential drug-drug interactions and its associated factors in the hospitalized cardiac patients. Saudi Pharm J. 2016;24:220-5.

38. Ibanez A, Alcala M, Garcia J, Puche E. Drug-drug interactions in patients from an internal medicine service. Farm Hosp. 2008;32:293-7.

39. Ismail M, Aziz S, Noor S, Haider I, Shams F, Haq l, et al. Potential drug-drug interactions in pediatric patients admitted to intensive care unit of Khyber Teaching Hospital, Peshawar, Pakistan: a cross-sectional study. J Crit Care. 2017:40:243-50.

40. Riechelmann RP, Moreira F, Smaletz O, Saad ED. Potential for drug interactions in hospitalized cancer patients. Cancer Chemother Pharmacol. 2005;56:286-90.

41. Amin M, Suksomboon N. Pharmacotherapy of type 2 diabetes mellitus: an update on drug-drug interactions. Drug Saf. 2014;37:903-19.

42. Steadman E, Raisch DW, Bennett CL, Esterly JS, Becker T, Postelnick M, et al. Evaluation of a potential clinical Interaction between ceftriaxone and calcium. Antimicrob Agents Chemother. 2010;54:1534-40.

43. Gaude GS, Chaudhury A, Hattiholi J. Drug-induced hepatitis and the risk factors for liver injury in pulmonary tuberculosis patients. J Fam Med Primary Care. 2015;4:238-43.

44. Ampadu HH, Asante KP, Bosomprah S, Akakpo S, Hugo P, Gardarsdottir H, et al. Prescribing patterns and compliance with World Health Organization recommendations for the management of severe malaria: a modified cohort event monitoring study in public health facilities in Ghana and Uganda. Malar J. 2019;18:36.

45. Santoshkumar RJ, Manjunath S, Sharanabasappa MA. Prescription pattern of anti-malarial drugs in a tertiary care hospital. Asian Pac J Trop Med. 2010;3:379-81. 
46. Malaria case management. https://dmc.gov.pk/documents/pdfs/Case_ Management_Guidelines.pdf. Accessed 7 Aug 2020.

47. Strategic Plan Malaria Control Program Pakistan (2015-2020). http://dmc. gov.pk/documents/pdfs/1National\%20Malaria-Strategic\%20Plan-Pakis tan.pdf. Accessed 7 Aug 2020.

48. National treatment guidelines for malaria, 2005. Islamabad, Pakistan, Ministry of Health, Malaria Control Programme Directorate/World Health Organization; 2005
49. Ray WA, Murray KT, Meredith S, Narasimhulu SS, Hall K, Stein CM. Oral erythromycin and the risk of sudden death from cardiac causes. N Engl J Med. 2004:351:1089-96.

\section{Publisher's Note}

Springer Nature remains neutral with regard to jurisdictional claims in published maps and institutional affiliations.
Ready to submit your research? Choose BMC and benefit from:

- fast, convenient online submission

- thorough peer review by experienced researchers in your field

- rapid publication on acceptance

- support for research data, including large and complex data types

- gold Open Access which fosters wider collaboration and increased citations

- maximum visibility for your research: over $100 \mathrm{M}$ website views per year

At BMC, research is always in progress.

Learn more biomedcentral.com/submissions 